\title{
RESEÑAS
}

\section{Reyes, Alejandro. Guerra del Pacífico. Soldados sobrevivientes, A-B.} Lima: S/e, 2018, 198 pp.

En el Perú, al igual que en Chile y Bolivia, la producción historiográfica sobre la Guerra del Pacífico es amplia. Sin embargo, estudios sobre la vida de los soldados que participaron en dicha guerra (antes, durante y después de ella) son todavía escasos. En este contexto, el libro del historiador Alejandro Reyes Flores, titulado Guerra del Pacifico. Soldados sobrevivientes. $A-B$, cubre un importante vacío historiográfico.

Como se puede leer en la introducción, este libro es el resultado de varios años de trabajo, el cual se inició en el 2005 en los repositorios del Centro de Estudios Histórico Militares del Perú (CEHMP). Desde ese entonces, el autor comenzó a rescatar la documentación producida por los excombatientes, quienes al amparo de las leyes dadas a su favor por los distintos gobiernos (desde fines del siglo XIX), buscaban obtener una pensión de parte del Estado en su calidad de sobrevivientes de la guerra del 79. Con esta información, Alejandro Reyes ha reconstruido la biografía de 291 excombatientes, cuyos apellidos corresponden a las primeras dos letras del abecedario (A y B). En este trabajo, según indica el autor, su labor como historiador ha consistido en «darle forma a los cientos de folios de los soldados sobrevivientes» (p. 24), para que las generaciones actuales $\mathrm{y}$ venideras puedan escucharlos y conocerlos.

¿Qué información encontramos en el libro? En principio, biografías de los excombatientes peruanos, las cuales han sido rastreadas a través de los documentos (expedientes personales). Gracias a Alejandro Reyes sabemos cuándo y dónde nacieron, quiénes fueron sus padres, en qué batallas participaron, qué hicieron después de la guerra, cuándo empezaron a tramitar su reconocimiento como excombatientes, qué tuvieron que hacer para probar su participación en la guerra, cuál fue el resultado de sus trámites, cuánto de pensión recibieron (los que la recibieron), dónde vivieron sus últimos años de vida, y finalmente, cuándo y dónde fallecieron. Pero no solo eso, luego de una paciente lectura, el lector podrá darse cuenta de que varios de los excombatientes participaron en el combate del Dos de Mayo (1866), que algunos resultaron heridos, que otros fueron prisioneros, que algunos apoyaron a Cáceres luego de la guerra, que algunos formaron parte de las guerrillas durante la Campaña de la Breña, que muchos estuvieron en más de una acción de armas, que varios no sabían leer ni escribir, etc.

Asimismo, de las biografías se puede deducir que algunos de los excombatientes eran todavía niños (de 11 años) o preadolescentes (de 12 ó 13 años) cuando estalló la guerra, que algunos solo buscaban ser reconocidos como asistentes o concurrentes a determinada acción de armas, que la mayoría de ellos pasaban los 60 años de edad (o incluso los 90 años) al momento de iniciar sus trámites ante el Estado y que, en algunos casos, cuando ya

(C) Los autores. Este artículo es publicado por ISHRA, Revista del Instituto Seminario de Historia Rural Andina de la Facultad de Ciencias Sociales de la Universidad Nacional Mayor de San Marcos. Este es un artículo de acceso abierto, distribuido bajo los términos de la licencia Creative Commons Atribución 4.0 Internacional (CC BY 4.0) [https://creativecommons.org/licenses/by/4.0/deed.es] que permite el uso, distribución y reproducción en cualquier medio, siempre que la obra original sea debidamente citada de su fuente original. 
habían fallecido, fueron sus viudas o sus hijos quienes buscaron el reconocimiento del Estado peruano.

Del mismo modo, se puede advertir que la extensión de las biografías varía entre una y otra. En algunos casos, éstas comprenden entre cinco o seis líneas y en otros, entre una o dos páginas. Desde luego, ello se debe a la cantidad de información encontrada en el documento. Sobre este punto, debe señalarse que Alejandro Reyes ha tratado de reconstruir la biografía de cada excombatiente en función de la información encontrada en su expediente personal. Así, la lógica parece haber sido la siguiente: a mayor cantidad de folios en el expediente, mayor cantidad de líneas en la biografía.

Por otro lado, es importante destacar la prosa del autor. Alejandro Reyes ha utilizado un lenguaje sencillo y claro, pensando siempre en el gran público. Por si fuera poco, ha incluido las fechas de cada una de las batallas o combates, lo que sin duda permite al lector ubicarse en el tiempo.

Otro mérito del libro es el rescate de las fotografías de nuestros excombatientes. ¿Cómo eran? ¿Qué rasgos étnicos tenían? ¿Cómo se encontraban al momento de realizar sus trámites ante el Estado? Gracias a Alejandro Reyes, conocemos -tal vez por primera vez- los rostros de 55 excombatientes. ¿Qué información podríamos obtener a partir de las mencionadas fotografías? Ésta es una pregunta que bien podría ser el inicio de futuras investigaciones.

Adicionalmente, se debe resaltar un hecho que suele pasar desapercibido: el financiamiento de la investigación y la publicación de la misma. Alejandro Reyes ha solventado con su propio peculio tanto la investigación como la publicación de su trabajo académico. Sin duda, una razón más para leer el libro materia de esta presente reseña.

Ahora bien, ¿qué perspectiva adopta Alejandro Reyes en su libro? Al respecto, podríamos decir que adopta la perspectiva de la llamada «historia desde abajo», es decir, de la historia que explora las experiencias de las personas cuya existencia a menudo se ignora, se da por supuesta o se menciona de pasada (Sharpe, 1996). La adopción de dicha perspectiva, sumado al trabajo con las fuentes de archivo, ha dado como resultado la visibilización de personas que por muchos años estuvieron relegadas al anonimato.

En relación con lo anterior, toca decir que el trabajo de Alejandro Reyes puede ser tomado como un primer acercamiento al conocimiento de los excombatientes. Al respecto, debemos mencionar que algunas de las biografías trabajadas por el autor fueron también trabajadas por Manuel Zanutelli Rosas (1982). Sin embargo, lejos de constituir una repetición, se podría decir que ambos autores presentan información que resulta complementaria.

De otra parte, hay algunos puntos que merecen algunos comentarios críticos. En primer lugar, el supuesto de que todos los biografiados son excombatientes o sobrevivientes de la Guerra del Pacífico. Si hacemos un resumen de los casos presentados, notaremos que del número total de excombatientes, menos de la mitad fueron reconocidos por el Estado como sobrevivientes y con derecho a pensión o montepío. En segundo lugar, la falta de un índice que ayude al lector a ubicar la biografía de cada excombatiente. En el libro solo se ha incluido un cuadro con tres columnas: nombre, lugar de nacimiento y acciones de guerra. Al parecer, con ello el autor intentó mostrar un resumen del libro. En tercer lugar, la inclusión de un Anexo que en realidad contiene más biografías de excombatientes (de la letra A). ¿Por qué no se incluyeron dichas biografías en el cuerpo del libro? En cuarto lugar, la falta de una bibliografía al final del libro. La inclusión de esta hubiese sido una gran ayuda para los investigadores interesados en la temática.

Los anteriores comentarios, desde luego, no desmerecen la importancia del libro para nuestra historiografía. Con esta nueva publicación, Alejandro Reyes contribuye al conocimiento de la Guerra del Pacífico desde una 
perspectiva bastante útil, para entender a los hombres y mujeres cuya existencia normalmente pasa inadvertida: «la historia desde abajo». Como es evidente, el libro reseñado permite responder algunas preguntas, pero también plantearse otras. Los historiadores nacionales y extranjeros encontrarán información valiosa para emprender otros trabajos de investigación.

Por nuestra parte, deseamos que el autor pueda continuar con su investigación y muy pronto nos entregue más biografías de nuestros excombatientes.

\section{Bibliografía}

Sharpe, J. (1996). La historia desde abajo. En P. Burke (Ed.), Formas de hacer historia (pp. 38-58). Madrid: Alianza Editorial.

Zanutelli, M. (1982). Los héroes de la Breña. En Comisión Permanente de Historia del Ejército, tomo 1 (pp. 71-153). Lima: Ministerio de Guerra, Comisión Permanente de la Historia del Ejército del Perú.

\section{Ale Roel Huillca Ayma}

ahuillca@cultura.gob.pe

Ministerio de Cultura

Publicado online: 10/08/2021 